\title{
Chemical Engineering via Art
}

\author{
Abraham Tamir*
}

Chemical Engineering Department, Ben Gurion University of the Negev, Israel

\begin{abstract}
The major aim of this article is to demonstrate via art different aspects of Chemical Engineering. This is a new approach developed by the author to describe scientific and engineering subjects via art, thus making them more understandable and easy to percept. The author has reached this conclusion after teaching several times a course on "The Interaction Between Art and Science" as well as writing articles in several scientific journals.
\end{abstract}

\section{INTRODUCTION}

First of all what is Chemical Engineering? According to Wikipedia, the free encyclopedia, "Chemical engineering is the branch of engineering that deals with the manufacture of products through chemical processes". Another definition reads: "Chemical engineering is the branch of engineering that deals with the application of physical science (e.g. chemistry and physics) and mathematics, to the process of converting raw materials or chemicals into more useful or valuable forms". Chemical Engineering grew out of mechanical engineering in the last part of the 19th century, because of a need for chemical processes.

Chemical Engineering has a wide scope of disciplines such as: Chemical reactions; Fluid dynamics; Mass transfer; Heat transfer; Separation of mixtures of chemical components; Control of process equipment; Thermodynamics of pure species and mixtures; Process safety; Biotechnology and Bio-engineering; Environmental engineering; Materials engineering; Food process engineering and Nano-particle technology. To achieve all above we need the Chemical Engineer whose aim is to be able to understand, design, build, and optimize complex industrial processes in a very wide range of fields, using the basic principles of mathematics, physics, chemistry, and other fields where necessary. This makes Chemical Engineers the most versatile type of engineer, and allows them to work in a very wide range of industries. Some highlights from the early history of Chemical Engineering are: 1859: John Glover, who designed the first mass-transfer tower, is often considered to be the first Chemical Engineer. 1880: George Davis, a Britain, founded the Society for Chemical Engineers, which failed. 1887: George Davis presented a series of 12 lectures on Chemical Engineering at Manchester Technical School. 1888: The first Chemical Engineering curriculum ever began at the Massachusetts Institute of Technology (MIT). 1901-1904: George Davis wrote a "Handbook of Chemical Engineering," which had over 1000 pages about unit operations. 1915: Arthur D Little recognized that filtration, heat exchange, distillation, and other assorted processes, which were used in different industries, were the same. This idea was called "Unit Operations". 1932: The American Institute of Chemical Engineers (AIChE) was formed.

\footnotetext{
*Address correspondence to this author at the Chemical Engineering Department, Ben Gurion University of the Negev, Israell;

E-mail: abr.tamir@gmail.com
}

\section{DEMONSTRATIONS OF CHEMICAL ENGINEER- ING BY ART}

In the following, demonstrations via art describe different aspects in chemical engineering. Fig. (1) shows a photo and caricature of John Hoover [1] (b. at about 1950), a chemical engineer, who solved technical problems for many companies. He also developed an automated internet-based business to help speed the job search process.

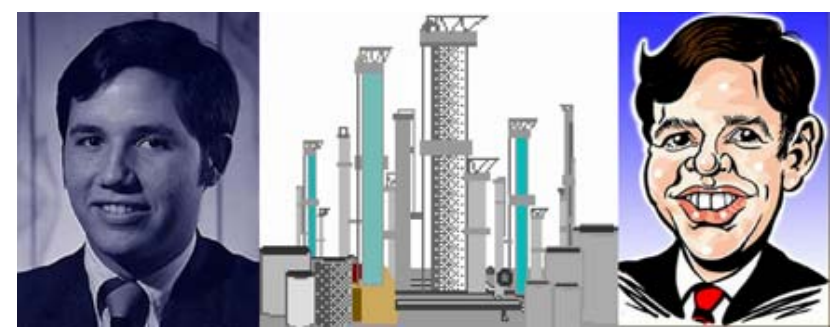

Fig. (1).

Between Hoover's portraits is a picture of some plant design that is the major occupation of a chemical engineer. Fig. (2) (left) is a picture of a real plant where on the righthand-side is an artwork entitled "American Landscape" [2] painted by Charles Sheeler (1883-1965), born in Philadelphia, who is recognized as one of the founders of American modernism. Undoubtedly the artwork demonstrates a chemical plant, although, according to the title, the artist probably did not intend to demonstrate such a plant.

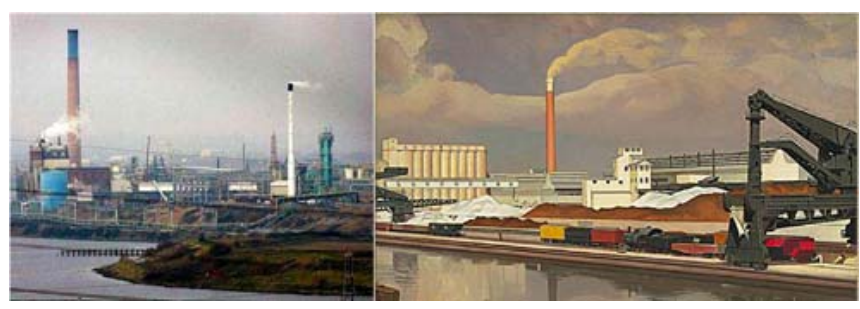

Fig. (2).

Fig. (3), "Sower with Setting Sun" [3], was painted by Vincent van Gogh (1853-1890) a Dutch Post-Impressionist artist. According to Wikipedia, Thermodynamics is the science dealing with the transformation of heat to work, which is the basis for all processes in chemical engineering. By examination of van Gogh's painting, it can be concluded that 
it indeed identifies with the above definition. The basic elements in Thermodynamics are processes, "reversible" and "irreversible". If a system moves from one state to the other through a series of small changes in each of which there is no change in the total entropy of the system and the surroundings, then it is a "reversible process".

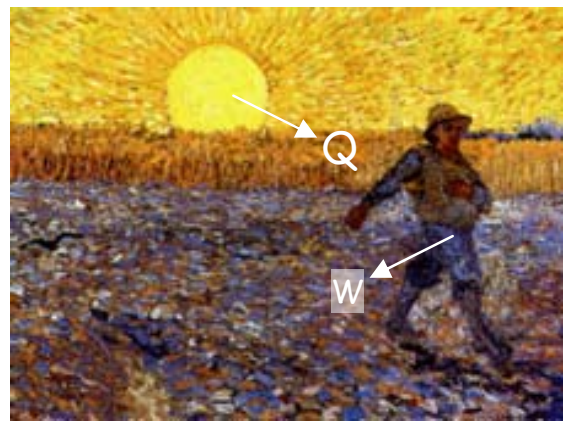

Fig. (3).

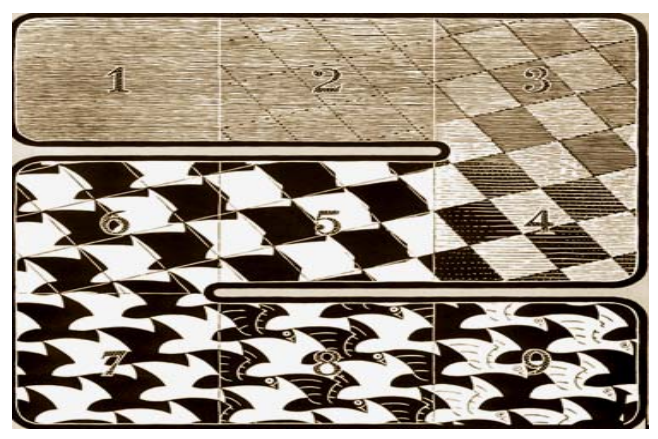

Fig. (4).

Fig. (4), "The Regular Division of the Plane" [4], was painted by Maurits Cornelis Escher (1898-1972), a Dutch graphic artist. One sees that squares are eventually transformed into birds at very small steps. Escher defines this process "metamorphosis". In other words, the change between two consecutive steps is very small, but after about 15 steps the above transformation is completed. Considering the above definition of a reversible process leads to the conclusion that indeed Escher's artwork demonstrates such a process. Another widespread process in chemical engineering is the "cyclic process" which is a combination of steps in which the initial and the final stage are identical. A famous process is the Carnot cycle. In Magritte's artwork "The Philosophical Lamp" [5] in Fig. (5) the nose, pipe and mouth form the cycle. Magritte was born in Belgium in 1898 and died in 1967 and is very famous as a surrealist artist. Another kind of a cycle is demonstrated in Fig. (6) entitled "Moebius band II" [6] painted by Escher. It demonstrates a ring-shaped band with the following characteristic. If one observes a certain ant crawling on the band, then he will observe that the ant will return exactly to the same place after two rotations, namely, a single cycle. This is because a ring-shaped band has usually two distinct surfaces one inside and one outside. However, this strip, as observed, has only one surface. Another cyclic process is demonstrated in Fig. (7). It is the Belousov - Zhabotinski "chemical cyclic reaction" [7] named after two Russian scientists where Belousov discovered the reaction in 1951. This chemical reaction occurs by mixing four compounds, which then create beautiful rings, which spread across the plate. The reaction oscillates back and forth between different colored states in rings, which move in rhythmic wave patterns. In the reaction ferroin continuously shifts and forms its oxidized form ferriin through different intermediate species. In the picture we see top views, at different times, of the surface of the apparatus in which the oscillatory chemical reaction takes place. Another kind of chemical reaction, "The Firework" [8], which combines art and science, is demonstrated in Fig. (8). Fireworks are usually made out of the following mixture: an oxidizing agent, a reủucing agent, coloring agent, binders and regulators. When these are mixed together and burned, they produce the spectacular effects.

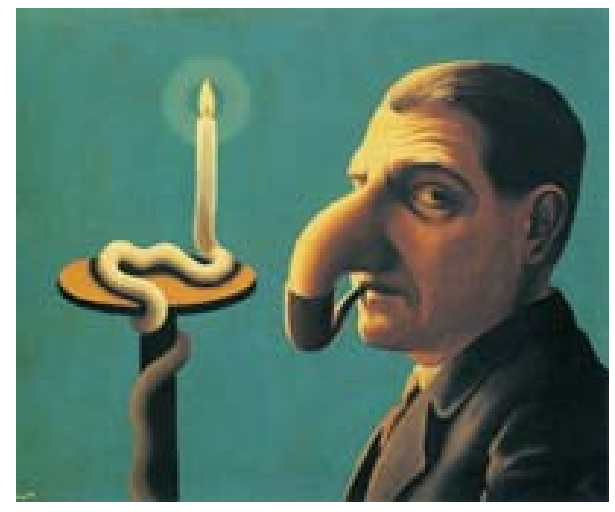

Fig. (5).

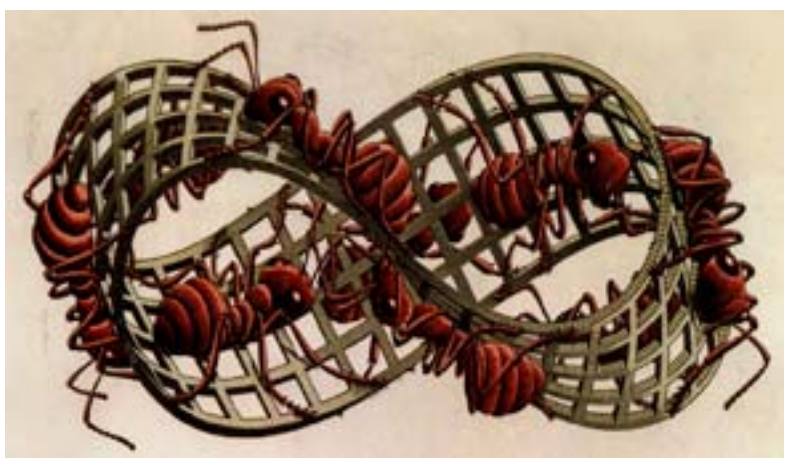

Fig. (6).

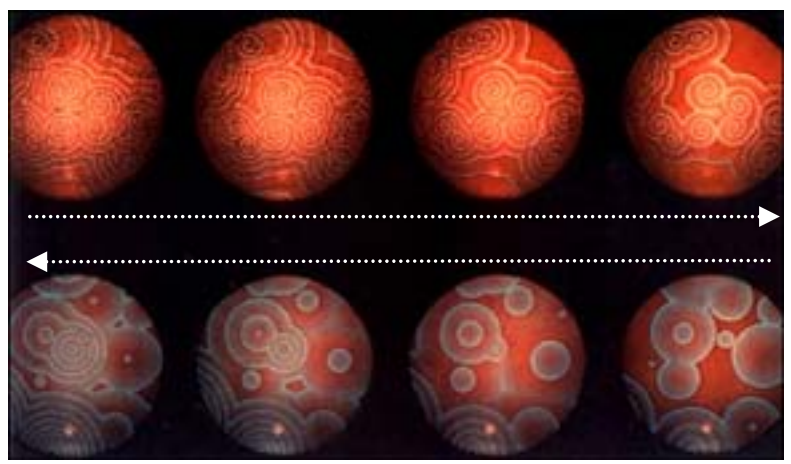

Fig. (7). 


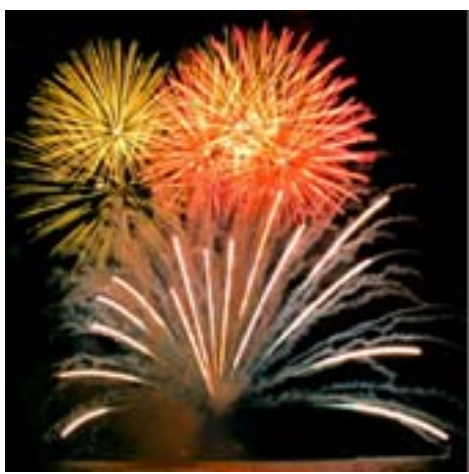

Fig. (8).

An artistic demonstration of the chemical reaction A yields B is shown in Fig. (9). It is entitled "Symmetry Work 72" [9] and painted by Escher where the two chemicals are demonstrated by two images. To conclude the subject of reactions, a humoristic demonstration of a chemical reactor is shown in Fig. (10).

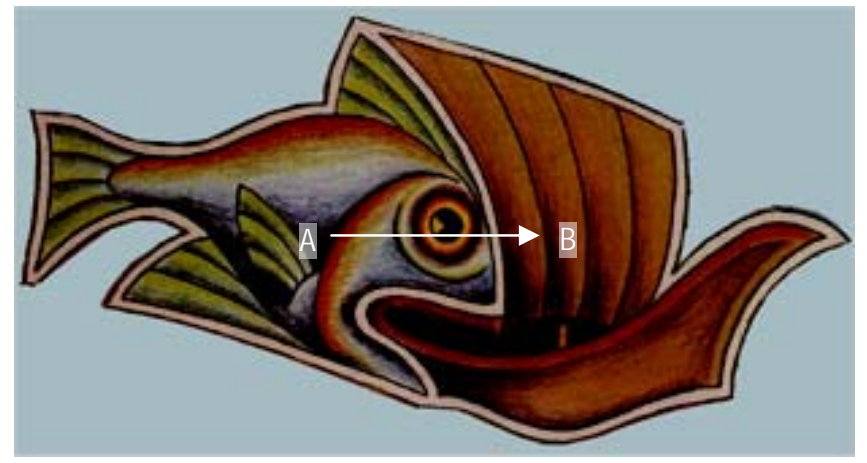

Fig. (9).

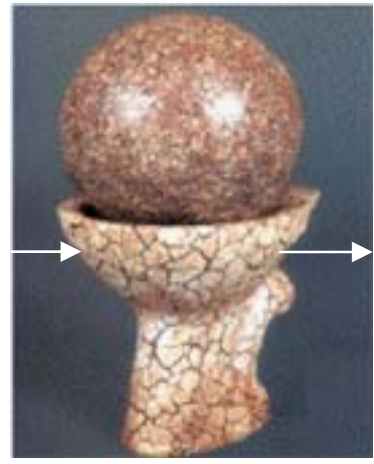

Fig. (10).

The basic states of matter in every process are solid, liquid and gas. These are demonstrated in Fig. (11) [10] for water that was photographed by Walter Wick (1953), an American artist and photographer. The artwork in Fig. (12) demonstrating these three states is the painting by the Spanish artist Jaime Morera Galicia (1854-1927) that is entitled "Snowy bank of Lake Trasimenco" [11]. This artwork demonstrates also an important subject in thermodynamics, the "Triple Point" of water consisting simultaneously of solid, liquid and vapor at $\mathrm{t}=0.098^{\circ} \mathrm{c}$ and 1 atmosphere. This unique point is also consistent with the "phase rule" indicating that the number of degrees of freedom for this point is zero.

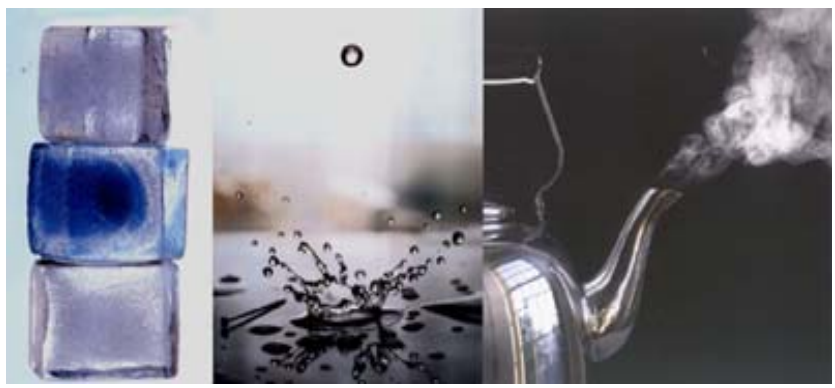

Fig. (11).

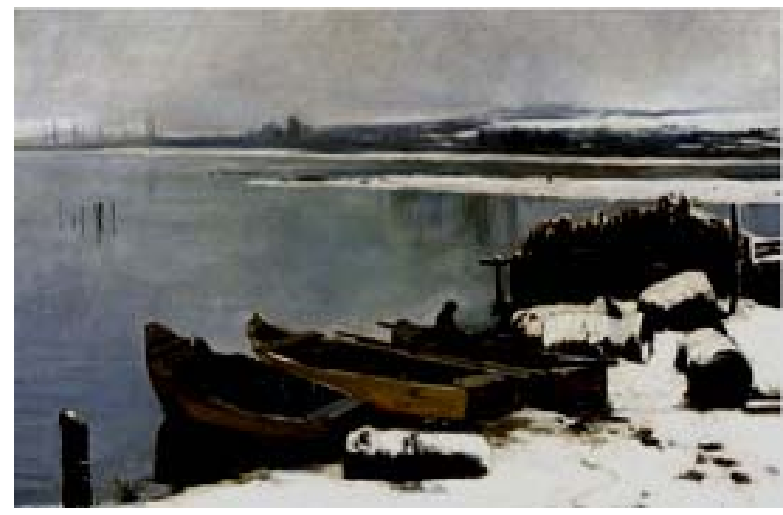

Fig. (12).

Another process in chemical engineering is combustion. It is a widespread process in industry related to a fast chemical reaction between the reactants, which generates heat, and light. In most cases one of the reactants is oxygen. The heat is utilized, for example, to generate electricity in power stations. Fig. (13) entitled "Eruption" [12, p.34] may demonstrate the combustion process. It was painted by Jacek Yerka (1952), a Polish surrealist artist who adds a remarkable twist of fantasy to his painting as demonstrated also in Fig. (24). When exothermic chemical reactions takes place, in which relatively large volume of gases are produced, explosion occurs. This is demonstration in Fig. (14) entitled "Explosion No.l" [13] painted by Roy Lichtenstein (1923-1997), a prominent American pop artist. Another demonstration of explosion appears in Fig. (15) entitled "Gaussian distribution, I' [14, p.146] painted by Anatoli Fomenko (1945), Ukraine Scientist-Art \& Mathematics. In this explosive image, large iron bars soar through space, emanating from a central source and flying about in all directions.

We refer now to a widespread subject in chemical engineering, the area of fluid flow demonstrated in Figs. (16-18) for the Daniel Bernoulli's liquid flow model. Fig. (16) is a well-known sculpture of Mannequin Pis created in 1619 that is Brussels landmark. It is a small bronze fountain sculpture depicting a naked little boy urinating into the fountain's basin. It is located on the corner of Stoofstraat/Rue de L'Etuve and the Eikstraat/Rue du Chêne. It should be emphasized 
that the action demonstrated by the Mannequin Pis is one of the most important operations of the human body that keeps it alive. Another demonstration of free flow enhanced by gravity is shown in Fig. (17). Hieronymus Bosch (c.14501516), a Netherlands Northern Renaissance painter, painted the artwork entitled "Allegory of Gluttony and Lust" [16]. It exactly coincides with the equation $v=(2 \mathrm{gh}){ }^{0.5}$. Fig. (18) is another painting by Anatoly Fomenko entitled "Homotopy and a Viscous Liquid" [14, p.154]. The artwork is an astounding demonstration of the flow of a viscous fluid dripping from above into an enormous space, where people run randomly about. In this image the underlying theme is homotopy, the way in which an object is continuously deformed without breaking.

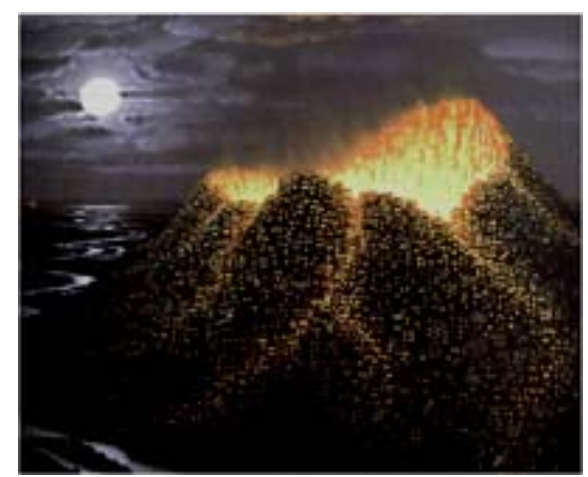

Fig. (13).

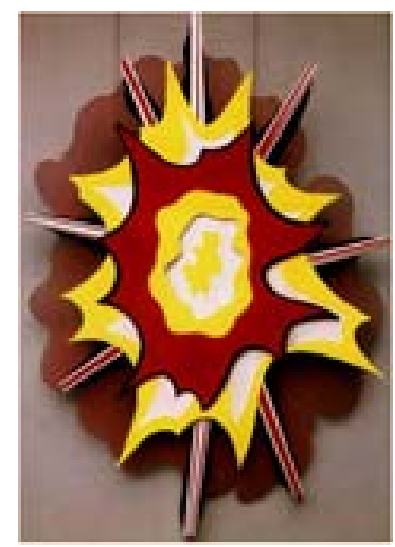

Fig. (14).

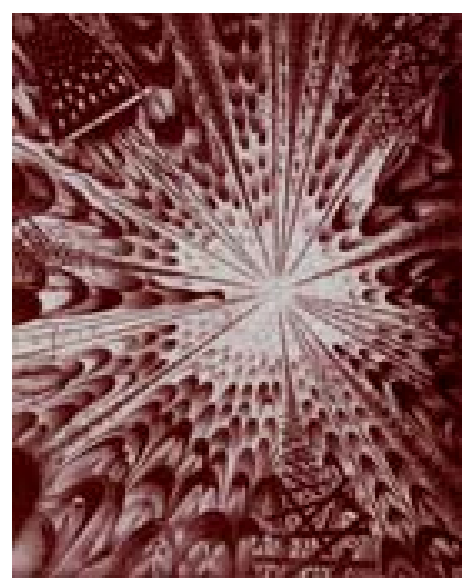

Fig. (15).

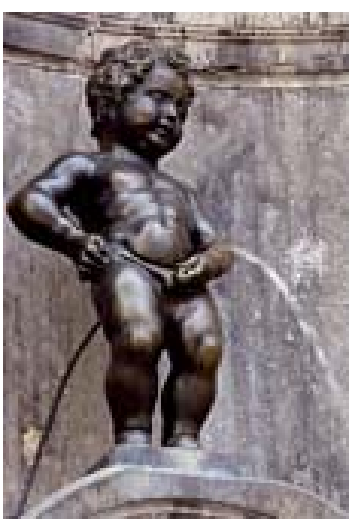

Fig. (16).

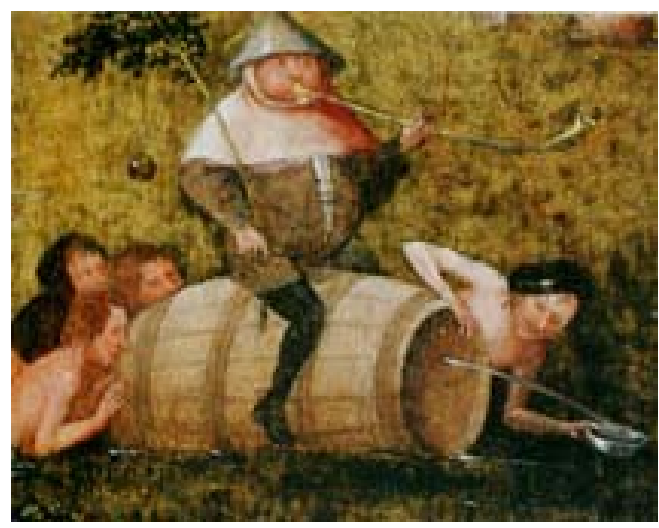

Fig. (17).

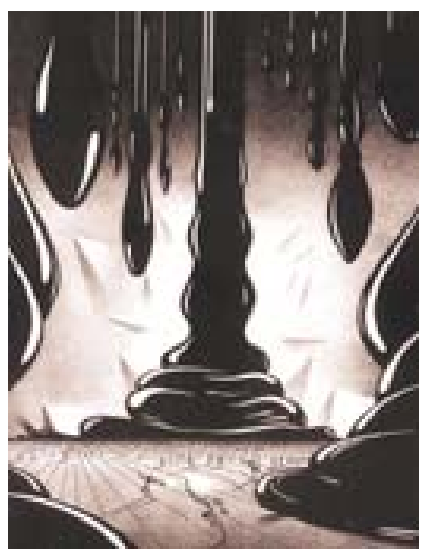

Fig. (18).

Diffusion, presented in Fig. (19) that was photographed by Walter Wick [10], is a random motion of molecules, which generates a net motion of matter from a high to a low concentration. On the left-hand side is a blue drop of water that is introduced into pure water. The molecules of the blue color undergo a diffusion process that causes, after some time, to formation of a solution with a uniform color as seen on the right-hand side. Fig. (20) entitled "The Sugar Mill" [17] is part of the original artwork painted by Diego Rivera (1886-1957), a Mexican Social Realist. It demonstrates the mixing process in chemical engineering. Fig. (21) demonstrates a pumping process by a combination of "Archimedes screw" [18] invented by Archimedes around $350 \mathrm{BC}$ and a 
pump as a device for transferring water upwards, for example for irrigation. It consists of a large spiral screw revolving inside a close-fitting cylinder. Leonardo da Vinci (14521519) who was a Tuscan polymath; a scientist, mathematician, engineer, inventor, anatomist, painter, sculptor, architect, botanist, musician and writer painted this artwork. He was born at Vinci in the region of Florence.

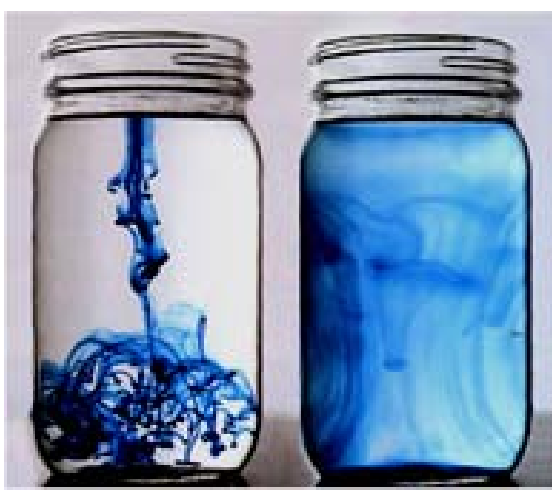

Fig. (19).

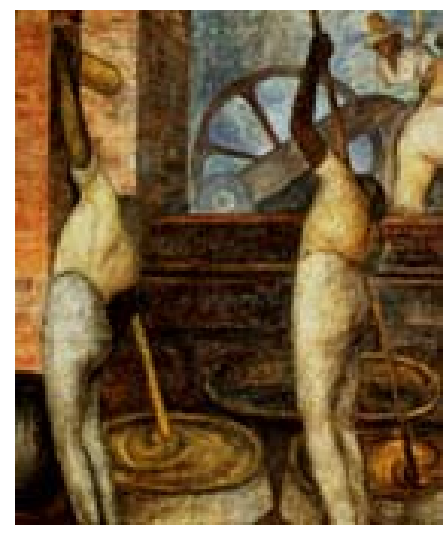

Fig. (20).

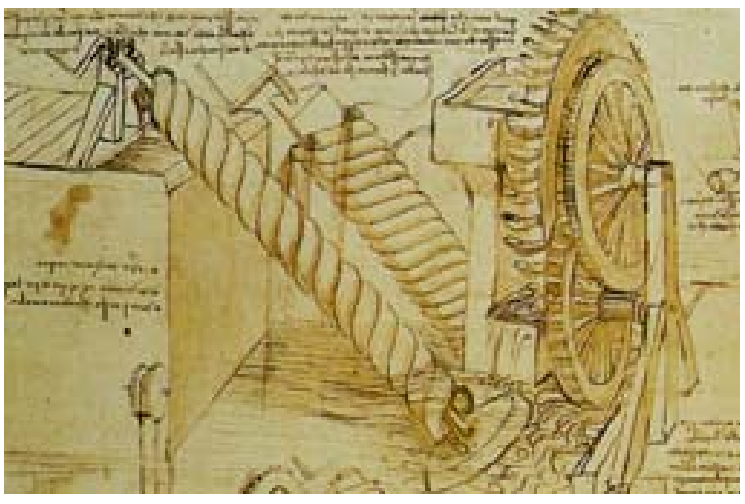

Fig. (21).

Fig. (22) painted by Magritte is entitled 'Heraclitus's Bridge" [19]. At first glance, it demonstrates the process of sublimation in which there is a direct transformation from a solid state to a gas state. The artwork demonstrates this process where half of the bridge underwent a sublimation process. However, after a thorough observation it is revealed that the artist generated an illusion of a sublimation process by covering half of the bridge by a cloud. M.C.Escher painted Fig. (23) entitled "Encounter" [20]. It demonstrates the engineering process of separation. In the back one sees a complete mixture of two kinds of "particles". Progress towards the front of the artwork reveals the separated mixture. Fig. (24) "Attack At Down" [12, p.4] is an astounding demonstration of Biotechnology, a scientific subject that forms a combination between biological sciences and subjects related to Engineering for industrial applications. The Polish artist Jacek Yerka (1952) painted it.

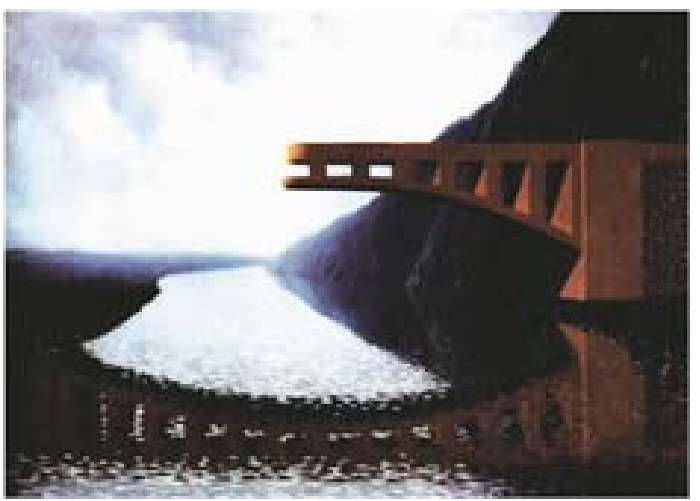

Fig. (22).

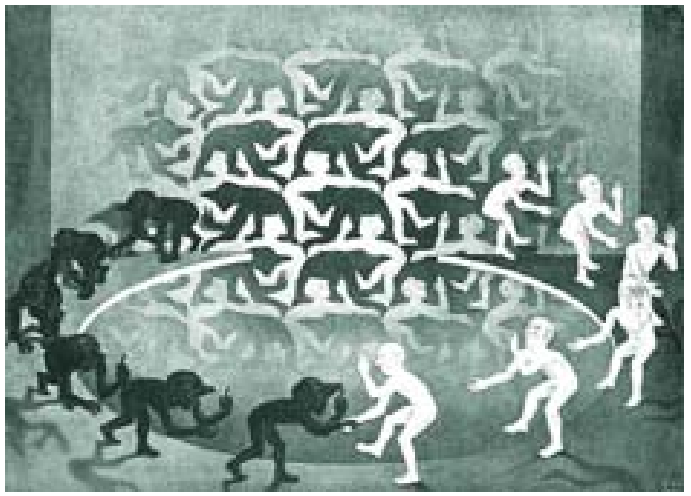

Fig. (23).

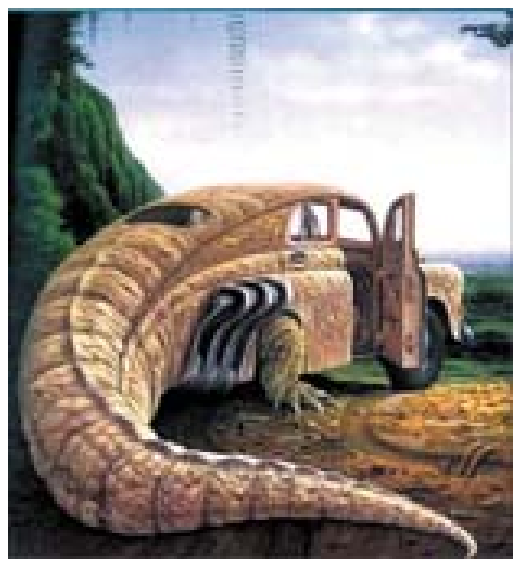

Fig. (24).

Fig. (25) terminates our artistic presentation by emphasizing a major point in perception. On the left-hand-side is a painting of an eye by Magritte entitled "The False Mirror" [21] on which part of the chemical plant in Fig. (2) was 
added. In this way the artwork demonstrates "seeing a chemical plant". However, seeing is only the $1^{\text {st }}$ step in the perception process where the final step is the fixation in the brain of what was transferred through the eye. This is demonstrated on the right-hand-side of Fig. (25) entitled "Vicera" [22] where on the original painting of Alex Grey the chemical plant is fixed in the brain forever. Alex Grey was born in 1953 in Columbus, Ohio and specializing in spiritual and visionary art.

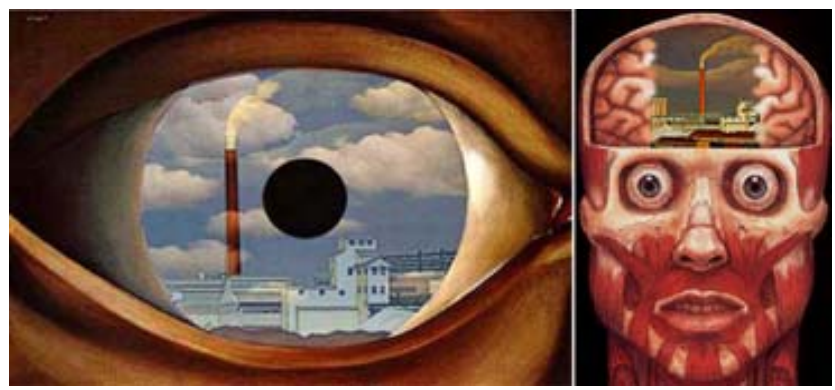

Fig. (25).

\section{CONCLUSIONS}

To conclude the article, the author believes that the presentation by artworks of the different areas in Chemical Engineering makes this profession clearer, more understandable, easy to percept as well as to remember. The article may also be used to present Chemical Engineering in a concentrated and attractive way to new students. Finally, and most important, the future of chemical engineering can be summarized by the following main objectives [23, 24]: (1) Increase productivity and selectivity through intelligent operations and multistage control of processes; (2) Design of novel equipment based on scientific principles and new production methods; (3) Implement multistage application of computational chemical engineering modeling and simulation to reallife situations from the molecular scale to the production scale; (4) Molecular manufacturing and commercialization of nanotechnology into useful products. (5) More chemical engineering graduates will be involved in new product development and catalysis research.

\section{ACKNOWLEDGEMENT}

The author would like to thank the reviewers for their constructive remarks that improved the presentation of the manuscript.

\section{REFERENCES}

[1] http://www.ecademy.com/account.php?id=87575

[2] http://wizardofthewest.blogs.com/iron_horses/2005/11/index.html.

[3] http://www.abcgallery.com/V/vangogh/vangogh35.JPG.

[4] http://mathsforeurope.digibel.be/Escher.html.

[5] http://maryannestahl.blogspot.com/2007/06/put-that-in-yourpipe.html.

[6] psychology.wichita.edu/.../ escher-moebius.gif.

[7] F.Frankel and G.M.Whitesides, On the surface of things, Chronicle Books, 85 Second Street, San Francisco, CA 94105, p.88.

[8] destinsharks.com/.../ bowlegs/fireworks-3.jpg.

[9] M.C.Escher, Escher on Escher, Exploring the Infinite, Harry N. Abrams, Inc., Publishers, 1989, p.27.

[10] W.Wick, A Drop of Water, Scholastic Press/New York, 1997.

[11] http://www.artehistoria.jcyl.es/genios/jpg/MOO01386.jpg.

[12] "Mind Fields", Morpheus International, 1994. http://home.att.net/ $\sim$ hoo12/Yerka/eruption.jpg.

[13] J. Hendrickson, Roy Lichtenstein, Benedikt Taschen Verlag GmbH and Co.KG, 1988, p. 18.

[14] A.T.Fomenko, Mathematical Impressions, American Mathematical Society, 1990, pp.146.

[15] http://www.tradcentre.com/shari/photos.html.

[16] http://www.abcgallery.com/B/bosch/bosch19.html.

[17] www.abcgallery.com/ R/rivera/rivera-2.html.

[18] www.windmillworld.com/ mills/improved.htm

[19] S. Whitfild, Magritte, The South Bank Center, 1992, p.66.

[20] http://www.globalgallery.com/enlarge/015-20781/.

[21] http://www.fotos.org/galeria/showphoto.php/photo/7375/size/big.

[22] Sacred Mirrors The Visionary Art of Alex Grey, Inner Traditions International, Rochester, Vermont, 1990.

[23] http://www.bepress.com/ijcre/vol1/A14/.

[24] http://findarticles.com/p/articles/mi_qa5350/is_200311/ai_ n21338882. 